\title{
DEVELOPING A STUDENT MENTAL HEALTH POLICY FOR A SOUTH AFRICAN UNIVERSITY: CONSULTATION, CONTESTATION AND COMPROMISE
}

\author{
D. Kaminer* \\ e-mail: debbie.kaminer@uct.ac.za
}

\author{
N. Shabalala* \\ e-mail: nokuthula.shabalala@uct.ac.za
}

*Department of Psychology

University of Cape Town

Cape Town, South Africa

\section{ABSTRACT}

Given high rates of student mental health difficulties globally, the need for universities to have a student mental health policy has been increasingly recognised. In the South African context, such policies must not only balance the mental health needs of students with the realistic constraints of university resources in a time of austerity, but also engage with complexities posed by the Global North foundations of the fields of psychology and psychiatry and the systemic determinants of mental health. This article describes the development of a student mental health policy at a South African university, with a focus on points of contestation that emerged out of a broad-based institutional consultation process. Areas of contestation included the scope of university support for student mental health, defining mental health difficulties, the use of a disability framework for mental health, and processes of verification. All of these were embedded within a broader tension between health and social justice discourses. The compromises that were designed to balance these complexities within the student mental health policy are discussed, and reflections are offered that may inform the development of student mental health policies at other South African universities.

Keywords: student mental health, policy, university, South Africa

In recent years there has been growing concern about a mental health crisis among university students (Brown 2018; Evans et al. 2018; Xiao et al. 2017). A World Health Organisation survey of university students across 21 countries found that one fifth $(20.3 \%)$ met criteria for a mental disorder in the past year (Auerbach et al. 2016). Further, mental health difficulties among university students appear to be increasing over time, far outstripping the capacity of campus counselling services (Brown 2018; Gallagher 2014). The need for formal university policies on student mental health has never been more urgent (Universities UK 2015). 
There are few prevalence studies of mental health difficulties among South African university students, but existing data suggest that 12 per cent experience moderate to severe symptoms of depression, 15 per cent have moderate to severe symptoms of anxiety and 24 per cent report suicidal ideation (Bantjes et al. 2016). In recent years, increasing rates of student suicides at South African universities (Mabasa 2018) have heightened the urgency of developing coherent institutional strategies to address student mental health needs.

In mid-2016, a Mental Health Task Team (MHTT) was established at the University of Cape Town (UCT) with the specific brief of developing a student mental health policy for the university. Although there had long been concern about unmet student mental health needs at UCT, the decision to establish a MHTT in 2016 was catalysed by the period of student activism that began in 2015. The Rhodes Must Fall (RMF) and Fees Must Fall (FMF) movements both included demands for better student mental health services as part of a broad transformation imperative for UCT (Faculty of Health Science students 2016; Rhodes Must Fall Movement 2015). The MHTT included representatives of the following university constituencies: the Student Wellness Service (SWS), the Disability Service (DS), faculty-based student development officers (SDOs), members of the Student Representative Council (SRC), members of a campus-based student mental health support group, academic staff, the university residences, and the deputy registrar's office. The authors of this article, both clinical psychologists, were members of the MHTT.

The process of crafting a student mental health policy involved university wide consultation over several months. There was a high level of engagement in the consultation process, during which several areas of contestation arose. These contestations were inter-related and can collectively be understood as emerging from a broader tension between two dominant discourses. This article will describe the process of developing a student mental health policy at UCT, the competing discourses that framed the policy development process, and four specific areas of contestation. We will end with some reflections that may be of value to other South African higher education institutions (HEIs) that are developing student mental health policies.

\section{PROCESS OF DEVELOPING A STUDENT MENTAL HEALTH POLICY AT UCT}

The MHTT began its work by conducting an internet survey of student mental health policies at other universities, and by reviewing best practice guidelines for university student mental health policies. At that time, in mid-2016, there were many student mental health policies available online, however most were from universities in high-income countries, primarily the United Kingdom (e.g. Oxford University 2017), Canada (e.g. University of Calgary n.d.) and Australia (e.g. University of Western Australia 2015). There was a dearth of such policies 
available online from low- and middle-income countries (LMICs), and none from South Africa. Follow-up telephonic contact with the student counseling / wellness services at other South African universities failed to identify any formal, dedicated student mental health policy documents, although, like UCT, some universities had just begun the process of developing one. The only available best practice guidelines for student mental health policies in higher education had been published by Universities UK (2015).

As existing student mental health policies and policy guidelines were based largely in Global North countries with different political, socioeconomic, cultural and higher education contexts than South Africa, the MHTT members conducted an institutional stakeholder review with campus service providers, students, academic staff and residence staff to explore student mental needs and services at UCT. Cross-cutting issues raised by all the stakeholders included in the review were as follows: 1) an increasing prevalence and complexity of student mental health difficulties at UCT over the past several years and a lack of capacity by campus service providers to keep up with the need for mental health services, 2) an institutional culture of silence about mental health issues, 3) communication and coordination difficulties between stakeholders, particularly with regard to roles and responsibilities, 4) discrimination and insensitivity by some academic and administrative staff towards students living with mental illness, and 5) a lack of awareness, or inaccurate information, about reasonable accommodations and concessions that are available to support students with mental health difficulties.

Based on the online review of student mental health policies and policy guidelines, and the stakeholder review at UCT, the MHTT began work on a draft student mental health policy. Simultaneously during 2016, in response to the urgent need for more services for students with mental health difficulties, the university funded more posts for mental health practitioners at the SWS, set up a toll-free 24-hour student careline, and activated mental health emergency support for student residences after hours.

The MHTT submitted a draft student mental health policy to the DVC for Transformation in April 2017. This draft was then circulated to all university members through various university communication platforms. For the next five months, a university-wide consultation process took place in which university members were invited to give input to the MHTT on the draft policy. This included an open meeting to which student representatives and UCT staff were invited, meetings with all the faculty boards, university residence structures and student governance structures, and consultation with the university's legal services. Further, an online survey was created through which all students were invited to anonymously contribute their feedback and suggestions. Based on all the inputs received, the MHTT revised aspects of the 
policy and submitted a final policy document to the DVC for Transformation in April 2018, which was subsequently approved by Senate and Council. The final version of the policy can be viewed on the UCT website at http://www.uct.ac.za/sites/default/files/image_tool/ images/328/about/policies/Student-Mental-Health-Policy.pdf

\section{COMPETING DISCOURSES}

Throughout the policy development and consultation process, two prominent discourses emerged. These can broadly be categorised as a health discourse and a social justice discourse. At first glance these discourses are not necessarily in conflict - health and wellness can be part of a social justice agenda, and both discourses can advocate for students' rights. However, these discourses are rooted in very different ideas about the causes of mental health difficulties in the student population and about what is needed to enhance student mental health within the institution. Their collocation posed a number of conceptual and practical tensions in development of the policy.

The health discourse reflects current approaches to mental health in LMICs promoted by the World Health Organisation (WHO) and the Global Mental Health Movement (GMHM), which argue that: mental health is part of general health, and access to mental health care, like access to basic health care, is a universal human right; barriers to accessing mental health care need to be removed; and promoting societal recognition and understanding of mental illness is key to improving the lives of those suffering from it (Patel 2012; 2014; Prince et al. 2014; WHO $2005 ; 2010)$. While there is acknowledgement that mental health has social as well as individual determinants, the current emphasis of the WHO and GMHM is on scaling up evidence-based psychotherapy and medication treatment for mentally ill individuals (Patel et al. 2007), rather than directly addressing the structural and systemic issues that impact on mental health (Whitley 2015). During the consultation process on the UCT student mental health policy, many stakeholders echoed the imperatives of the WHO and GMHM, arguing that mental health is a real and legitimate student health issue that is part of wholistic student wellness, that stigma and discrimination about mental illness need to be addressed by promoting recognition and understanding within the institution, that there is a need to remove barriers to the academic inclusivity of students with mental health difficulties, and that better resources and access to mental health services and support are needed. This approach assumes a medicalised and individualised view of student mental illness as a health disorder located within individuals, which should be understood, accommodated and, as far as possible, treated by the institution.

The social justice discourse that emerged during the policy development process reflected the tenets of decolonial theory (Bulhan 2015; Titchkosky and Aubrecht 2009), liberation 
psychology (Fanon 1991; Martín-Baró 1994) and critical psychiatry (Bracken, Giller and Summerfield 2016; Kirmayer and Gold 2012; Mills 2015), which have all argued that the roots of psychological distress often lie in systems of social oppression, structural violence and collective trauma, rather than individual dysfunction. The student protest movements at UCT (RMF 2015), submissions from students and staff to UCT's Institutional Reconciliation and Transformation Commission (IRTC 2019), and inputs from university members during discussions about the student mental health policy proposed that "mental health difficulties" among black students at UCT are often a proxy for systemic inequality and exclusion within a historically white institution. Examples of such systemic experiences have been documented in detail elsewhere (see Cornell and Kessi 2017; IRTC 2019; Swartz et al. 2018). Within this discourse, the apparent crisis of student mental health at UCT does not reflect an increasingly "mentally disordered" student population but, rather, failures of institutional transformation. The medicalisation and individualisation of student mental illness, and an emphasis on individual treatment, serve only to maintain systems of institutional oppression. Addressing student mental health difficulties requires meaningful transformation of the entire institution.

The ways in which these different discourses manifested through different areas of contestation will now be considered.

\section{THE UNIVERSITY'S ROLE IN SUPPORTING STUDENT MENTAL HEALTH}

An overarching issue that framed many of the discussions within the MHTT, and during the consultation process, concerned the university's role and responsibility in addressing the mental health needs of its students. Like many LMICs, South Africa's state mental health service is inadequately funded, receiving only a negligible percentage of the national health budget (Lund et al. 2010). In practice, this means that South Africans who cannot afford private mental health services have little access to a mental health practitioner. Consequently, many students at UCT and other South African universities have no choice but to rely on campus mental health facilities as their sole service provider. When campus services have a waiting list of several weeks, student mental health difficulties can escalate into more serious crises.

From a health service framework, some UCT stakeholders argued that it is unrealistic to expect universities to provide a substitute mental health system capable of plugging the enormous gaps in state service provision. In UCT's case, this would entail providing mental health services that can cater for a population of about 27,000 students, with little augmentation from the state health sector. In the current climate of shrinking government funding for universities in South Africa (Bozzoli 2015), allocating more funding to student mental health means that resources may have to be diverted from other transformation imperatives in higher 
education. These include academic support programmes, bursaries for the "missing middle", and curriculum change initiatives, all of which aim to address issues that likely contribute to student distress levels in the South African context.

On the other hand, but still within a health discourse, it may make good financial sense for universities to invest in students' mental health. South African mental health researchers have demonstrated that the cost to the economy of not providing adequate treatment for depression and anxiety disorders in the general population is far higher than the estimated costs of treating them, due to lost productivity and lost earnings (Lund et al. 2013). This is likely true for the higher education setting also. The effects of mental illness on the productivity of university students are well-documented in international studies: mental health difficulties hinder 18 per cent of undergraduates and 14 per cent of postgraduates from meeting their current academic obligations (Eisenberg et al. 2007) and, in longitudinal research, depression amongst college students predicts both lower academic performance and a higher risk of attrition (Eisenberg, Golberstien and Hunt 2009). A recent review of re-admission appeal applications from academically excluded students at UCT found that 17 per cent of readmission applications were motivated by the presence of a verified mental health disorder during the year in which the student failed (Ngubane 2019). The impact of mental health difficulties on student throughput has direct cost implications for South Africa universities in terms of lost subsidy. On a purely economic basis, universities cannot afford not to address student mental health needs, and investing in student mental health will likely pay for itself via improved student throughput rates.

From a social justice position, student activists have argued that UCT has an obligation to provide psychological support for students who have suffered, and continue to suffer, the collective trauma of racism (RMF 2015), including experiences of racism within the institution itself (IRCT 2019). Others have proposed that mental health support is one component of establishing a community of care to promote holistic student development and combat the potentially alienating effects of the increasing commodification of the higher education sector (Brooks 2018). Indeed, the economic argument that mental health support will "pay for itself" via better throughput rates reflects the commodification of students - within a social justice discourse, such economic considerations are another manifestation of institutional violence.

In trying to find a middle ground between these positions, we suggest that there are compelling economic and ethical motivations for universities to provide mental health support to their students. However, universities need to find the most cost-effective and sustainable ways of doing this. Student mental health services at UCT, like universities in many other countries (Brown 2018), have historically adopted a cost-intensive model of treating individual 
students who have already developed symptoms of mental illness. Following the WHO's (2013) recommendations for mental health policy in LMICs, a more sustainable, cost-effective approach would be to invest in primary prevention initiatives, rather than only treating already symptomatic students (Tol 2015). Primary prevention includes mental health promotion strategies (enhancing mental wellness) and the prevention of new cases of mental illness by addressing the main risk factors or drivers of mental illness in the population (WHO 2002).

In the policy, mental health promotion and prevention were included in the core responsibilities of the SWS and the DS. However, given the importance of social context in shaping mental health (Kirmayer and Pedersen 2014), it is important that mental health promotion and prevention strategies do not place the responsibility for optimal mental health solely on students (for example, by developing better sleeping, eating and stress management behaviours, within a health/wellness framework); they must also address systemic institutional issues that affect student mental health, in line with the social justice discourse (Dolmage 2017). Prevention efforts at universities should target all modifiable risk, protective, and promotive factors in the institutional environment, in addition to individual level factors. In this way, mental health promotion and prevention is not the sole responsibility of campus mental health service providers, but of the entire institution through broad-based transformation processes.

\section{DEFINING "MENTAL ILLNESS”}

Upon beginning to draft a student mental health policy, the MHTT was immediately confronted with the complexity of defining the concepts that would underpin the policy. As experiences of transient distress or anxiety are a normal part of the human experience (Frances 2013), and will therefore affect many students at various points, which mental health difficulties should fall within the scope of the policy? From a health perspective, mental disorders can be distinguished by whether symptoms reach a "clinically significant" level (American Psychiatric Association 2013). But who gets to judge this, and how?

There are no clear biophysical markers for most mental illnesses in the way that there are for many physical illnesses (Insel 2013). So how do we know when "mental disorder" or "mental illness" is present? The concept of "mental disorder" has long evaded a consensual operational definition, yet mental health nosological systems continue to attempt to divide people into the mentally well and the mentally disordered (Frances and Widiger 2012). Over time, new mental disorders have been introduced into psychiatric classification systems such as the Diagnostic and Statistical Manual for Mental Disorders (DSM) (American Psychiatric Association 2013). This has led to widespread concern that common, expectable human experiences are increasingly being pathologised as "disordered" by a small group of experts, 
mainly representing white, male-dominated, heteronormative American psychiatry, often using arbitrary criteria with little supporting evidence (Frances and Widiger 2012; LaFrance and Mckenzie-Mohr 2013; Summerfield 2002). Others have argued that the whole endeavor of categorising mental illness as either absent or present is invalid because mental experiences always lie along a spectrum; dimensions like the frequency and severity of certain experiences (such as low mood, or feelings of anxiety) are therefore more useful indicators of a need for clinical attention than just their presence or absence (Lopez, Compton, Grant and Beiling 2007).

Beyond these boundary debates, the literature on decolonising mental health has critiqued the tendency of Western/Northern mental health classification systems to marginalise or completely elide indigenous forms of mental distress found outside of the Global North (Mills 2015; Watters 2010). For instance, in the DSM 5 (American Psychiatric Association 2013), examples of "cultural concepts of distress" are included only in an appendix, indicating that the DSM views Western/Northern psychology as the human norm (Murphy 2015). Further, this literature has argued that "clinically significant" distress is often a normal and appropriate response to systems of oppression and structural violence, rather than a symptom of individual disorder (Mills 2015).

The MHTT's attempts to clarify the scope of mental health difficulties that would be encompassed by the policy were informed by these debates. Within a health discourse, many UCT stakeholders argued that some mechanism is needed for distinguishing distress that is genuinely affecting a student's ability to function from the normal, passing stress, distress and anxiety that most students experience at times (such as unpleasant but not incapacitating feelings of anxiety during times of stress, or transient low mood that many people experience without any notable impact on their functioning). It was argued that decisions about the appropriateness of access to both academic concessions and treatment resources rest on the need for there to be more than a "normal" level of stress or distress. Psychiatric classification systems provide such a mechanism in the form of clinical thresholds for diagnosing mental disorder. However, others in the university community proposed that psychiatric diagnoses are Northern/Western constructions that label and stigmatise people, fail to adequately capture local expressions of distress, and function to medicalise normal responses to oppressive systems. These arguments are located within a social justice discourse.

The MHTT recognised the need to distinguish between normal, transient feelings of distress and the presence of more debilitating mental health difficulties, but also acknowledged that using a narrow definition based on the presence of a diagnosed psychiatric disorder from a Northern/Western nosological system like the DSM may be contextually inappropriate. After a number of different iterations, the MHTT eventually settled on the following definition of a 
mental health difficulty, which draws from the South African Employment Equity Act Revised Draft code of Good Practice for the Employment of Persons with Disabilities (2015): "a clinically recognised condition or illness that affects a person's thought processes, judgment or emotions, and causes clinically significant distress and/or impairment in social, occupational or other important areas of functioning". This broad definition encompasses conditions that are recognised within a clinical framework, which may include Northern psychiatry or local traditional health frameworks, and are of sufficient severity to substantially limit the student's functioning. The potential causes of these difficulties are not defined, since these may vary across students. Any student experiencing mental health difficulties as defined above, whatever the cause, is encompassed by the policy. The preamble of the policy recognises that the causes of mental health difficulties may include systemic and structural factors along with individual factors.

\section{A DISABILITY FRAMEWORK}

Related to the issue of definitions, the MHTT debated the benefits and disadvantages of defining chronic mental illnesses (lasting longer than 12 months) within a disability framework in the policy. These debates considered whether the potential benefits of the legal rights afforded to persons with disability offset the potential harms that the disability label carries.

Within a global health framework, the GMHM identifies mental illness as a leading cause of disability globally (Whiteford et al. 2015). In international and local law, the term "disability" affords specific rights aimed at ensuring equality and redress for people with impairments, who have historically been excluded, marginalised and discriminated against. The UN Convention on the Rights of Persons with Disabilities (UNCRPD) (United Nations General Assembly 2007), to which South Africa is a signatory, recognises persons with disability as those "who have long-term physical, mental, intellectual or sensory impairments which in interaction with various barriers may hinder their full and effective participation in society on an equal basis with others" (Article 1). Importantly, it recognises that disability results from the interaction between persons with impairments and attitudinal and environmental barriers (Preamble [e]). The UNCRPD further recognises that persons with disability have a right to education without discrimination on the basis of equal opportunity (Article 24). It requires state signatories to ensure that all persons with a disability receive the necessary support and reasonable accommodations to facilitate their effective education (Article 24, 2).

In South Africa, the Constitution of South Africa (1996, sections 9(3) and 9(4)) and the Promotion of Equality and Prevention of Unfair Discrimination Act (2000, section 9) legislate that persons with disabilities have a right not to be unfairly discriminated against. The recent 
Strategic Policy Framework on Disability for the Post-School Education and Training System (2018) provides a guide for the improvement of access to, and success in, post-school education and training for people with disabilities.

There is therefore a strong legislative and policy framework that could be drawn upon by university mental health policies in South Africa to ensure that the rights of students with longterm mental health difficulties are protected, and that students do not need to rely solely on the subjective willingness of academic or administrative staff to view their mental health needs as "legitimate". At UCT, students who have disabilities can register with the DS for long-term academic accommodations across all their courses, and DS can then advocate on their behalf if academic departments fail to offer reasonable accommodations.

While disability legislation aims to protect the rights of persons with disability, and therefore can be said to advance a social justice agenda, the term "disability" and its various definitions have been contested from numerous positions that also fall within a social justice framework. These include, but are by no means limited to, the following arguments: the term "disability" itself carries stigmatization and can result in processes of marginalisation and discrimination (Shifrer 2013); the disability framework locates physical, mental or cognitive differences as deficits residing within individuals, rather than problematising the processes of social oppression that impose restrictions on the activities and identities of people with impairments (Goodley 2018; Thomas 2007); disability studies have historically been dominated by Northern knowledges and have largely excluded Southern theories (Grech 2015); and the disability framework allows universities to treat students with impairments in a legalistic manner, providing only the minimum accommodations that are required to avoid litigation (Dolmage 2017).

While holding all the above concerns in mind, the MHTT ultimately elected to explicitly define long-term mental health difficulties as disabilities in the policy, using the definition in the UNCRPD which recognises that disability (as opposed to impairment) is located within environments and not within persons. Defining mental health within a disability framework entailed a deliberate choice to foreground the university's legal obligations to protect the rights, and support the needs, of UCT students living with long-term mental health conditions. The policy emphasises that this group of students has the same right to register with the DS, and receive long-term academic accommodations, as do students with more visible impairments.

At the same time, the MHTT realised that the policy needed to mitigate the potential harms that a disability framework might create, by ensuring ethical management of disclosure of students' disability status, preventing discriminatory practices against students registered with DS, and changing staff and student attitudes towards students with a mental health disability 
through training, awareness and promotion activities. These issues are addressed across different sections of the policy. However, it may be argued that the policy still maintains an ableist institutional discourse through the use of the term "disability", a tension that the MHTT was not able to successfully resolve.

\section{VERIFICATION OF MENTAL HEALTH DIFFICULTIES}

In the development of the student mental health policy, there was also vigorous debate about the need for students to provide verification of their mental health difficulties to access academic concessions such as assignment extensions, deferred exams, adjusted curriculum load, and leave of absence, and to register with UCT's Disability Services for long-term reasonable accommodations.

Many academic staff were concerned that allowing concessions upon student request, without any verification of mental health difficulties, would place academic staff in an untenable position. In the absence of supporting documentation, academic staff are left to subjectively judge which applications are "legitimate". While staff recognised that many students have genuine mental health difficulties, they were also aware that other students try to "game the system" by requesting concessions on mental health grounds that are not genuine. Academic staff objected to having to police the boundary of "legitimate" or "reasonable" requests for concessions on mental health grounds, seeing this as beyond, and potentially in conflict with, their role as educators. They believed these judgements are best made by those with training in mental health issues, in the same way that student requests for concessions on physical health grounds rely on medical verification. The arguments for verification thus draw upon a health discourse that posits medical expertise as necessary to make judgements about the legitimacy of mental health difficulties.

By contrast, many students proposed that students should be able to autonomously and agentically judge for themselves when they may need an academic concession due to being incapacitated by mental health difficulties, without needing confirmation from "experts". First, for many students, health or mental health experts are often hard to access due to long waiting lists at SWS and a lack of funds for private practitioners; access to verification is therefore not always equitable. Second, students commonly expressed their resistance to having to perform their mental health difficulties in particular, expected ways in front of health professionals to receive the necessary documentation to access academic accommodations or concessions (much as students often feel forced to perform their poverty to various institutional committees or administrators to receive financial support). The need for performance and expert verification is experienced as a demeaning and unnecessary barrier to real academic inclusivity for students 
experiencing debilitating stress and distress, particularly when these arise in part from systemic and institutional inequalities. This process of "bio-certification", whereby mental health difficulties only become constituted as "real" through a process of medical and legal verification, has been problematised in the disability studies literature as a feature of academic ableism (Dolmage 2017; Samuels 2014). The arguments against verification thus draw upon a social justice discourse that views students as agentic experts on their own needs and "biocertification" as a bureaucratic barrier to real academic inclusivity.

The MHTT adopted the position that some form of verification beyond the student's own testimony should be required to receive academic accommodations and concessions on mental health grounds. The onus placed on students to provide this verification is balanced by the onus placed on academic and administrative staff to accept genuine verifications and respond with reasonable concessions. This requirement both reduces the risk of students "gaming the system" and reduces possible biases that could result from academic staff and university administrators subjectively adjudicating concession applications on the grounds of mental health difficulties. It is also in line with the university's requirements for obtaining concessions on physical health grounds, establishing mental health as a legitimate and equal aspect of general health. In the policy, the range of experts from whom verification can be obtained includes mental health practitioners, general health practitioners or traditional health practitioners, who are registered with a recognised statutory authority. The additional posts at the SWS aimed to enhance equitable access to mental health practitioners for all students.

\section{REFLECTIONS AND RECOMMENDATIONS}

The tensions between the health and social justice discourses, which reflect broader debates in the global mental health field, repeatedly raised questions for the MHTT about the aim, purpose and scope of a student mental health policy. Can health and social justice imperatives complement each other in such a policy, or are they fundamentally (epistemologically) opposed? Should student mental health policies aim to regulate transformation of all the institutional drivers of mental health difficulties, or only to augment institutional transformation policies? The MHTT found no clear answers to these questions. However, some reflections on the process are offered below, which may be of value for other HEIs in South Africa.

Based on our experience with the MHTT at UCT, we strongly advocate for universities in South Africa to develop formal student mental health policies. University students are vulnerable to experiencing mental health difficulties due to both their developmental stage and the multiple challenges posed by the structural and systemic inequalities that still characterise the higher education sector in South Africa. Failure to recognise and address this risks a range 
of harms to both students and institutions. We consider a formal student mental health policy to be part of a university's ethical responsibility to its students.

Based on the experience of the MHTT at UCT, a policy development team that represents a range of different voices within the university is essential for engaging openly with the complex issues involved. Further, broad institutional consultation beyond the policy development team is valuable in facilitating a sense of collective crafting and ownership of the policy. However, consultation raises contestation and complexity that require careful holding and thinking through. Mental health is not a neutral subject; it raises feelings of vulnerability, distress, fear and anger across institutional stakeholders. As psychologists on the MHTT, we observed a range of individual and institutional defences against the pain and discomfort of talking about mental health. We observed that these defences can lead to blame-shifting, psychological "splitting" (Klein 1946) into talk of "us" and "them", and what the psychoanalyst Wilfred Bion (2018) has referred to as attacks on thinking. We ourselves engaged in these defences at times. Such defences need to be recognised, understood and carefully metabolised by the policy development team so that the team can stay responsive rather than reactive.

In engaging with the tensions between the health and social justice discourses, the MHTT grappled with the degree to which the policy should balance strategic, pragmatic and transformational goals. In our institutional engagements, we heard much talk of "policy fatigue", arising from previous experience of university policies that make ambitious promises but are not adequately implemented. We wondered whether it would be better to have moderate policy aims (more in line with the health discourse described above) that have a stronger chance of being implemented and monitored, or whether this would be insufficient to effect meaningful change in the mental wellbeing of students (as the social justice discourse cautions). We wanted to be aspirational in addressing both health and social justice issues but, as illustrated in the areas of contestation described above, we often found that these can pull in different directions.

As is evident from the decisions that were ultimately made about each area of contestation, the final version of the UCT student mental health policy largely reflects aspects of the health discourse, advancing rights to academic inclusivity and institutional support for students with acute and long-term mental health difficulties. The policy commits UCT to providing an inclusive educational environment that welcomes mental health diversity and reduces barriers to the equal participation of students with mental health difficulties in academic activities and broader university life. Further, the policy commits UCT to providing interventions for students with acute and chronic mental health difficulties, to promoting student mental health, and to reducing the onset of new mental health difficulties. This was a strategic decision aimed at maximizing the likelihood of meaningful implementation. There was concern that attempting 
to regulate broad aspects of institutional transformation through the mental health policy itself would result in a policy that lacked a clear focus, hampering the likelihood of successful implementation. Rather, the policy was envisioned as supplementing existing and ongoing institutional transformation processes, including the IRTC, the curriculum change framework, the university's strategic plan, policies on employment equity, racism and sexual harassment, and existing university structures focused on transformation (University of Cape Town 2018).

The UCT student mental health policy is not a complete solution to addressing student mental health at the university; it is just a step in the direction of doing so. The policy is only one facet of what should be an ongoing, sustained process of institutional engagement with student mental health that aims to address both health and social justice imperatives through multiple mechanisms. Further, it is not a static document but rather one that will be monitored, reviewed and revised as needed in the years to come. It is also important to recognise that policies that specifically address staff and worker mental health are an integral part of institutional transformation and institutional health.

Other South African universities may find that their institutional needs for student mental health require a different set of policy commitments than those contained in the UCT student mental health policy, with a different balance or alignment between health and social justice goals. We have shared the process of developing a student mental health policy at our institution not necessarily as an optimal model to be followed, but in recognition that South African HEIs can learn lessons from each other's experiences in developing policies to nurture the mental health and well-being of our students.

\section{REFERENCES}

American Psychiatric Association. 2013. Diagnostic and Statistical Manual of Mental Disorders. $5^{\text {th }}$ Edition (DSM 5). Washington, D.C.: American Psychiatric Association.

Auerbach, R. P., J. Alonso, W. Axinn, P. Cuijpers, D. Ebert, J. Green, ... P. Mortier. 2016. Mental disorders among college students in the World Health Organization world mental health surveys. Psychological Medicine 46(14): 2955-2970.

Bantjes, J. R., A. Kagee, T. McGowan and H. Steel. 2016. Symptoms of posttraumatic stress, depression, and anxiety as predictors of suicidal ideation among South African university students. Journal of American College Health 64(6): 429-437. doi:10.1080/07448481.2016.1178120

Bion, W. R. 2018. Second thoughts: Selected papers on psychoanalysis. London: Routledge.

Bozzoli, B. 2015. Behind the university funding crisis. http://www.politicsweb.co.za/news-andanalysis/behind-the-university-funding-crisis (Accessed 3 May 2019).

Bracken, P., J. Giller and D. Summerfield. 2016. Primum non nocere. The case for a critical approach to global mental. Epidemiology and Psychiatric Sciences 25: 506-510.

Brooks, E. 2018. Criminalising students who protest(ed) - do we care? A student affairs practitioner's perspective. Paper presented at the University of Cape Town Teaching and Learning Conference, University of Cape Town, July 2019.

Brown, J. S. L. 2018. Student mental health: Some answers and more questions. Journal of Mental 
Health 27(3): 193-196. doi:10.1080/09638237.2018.1470319

Bulhan, H. 2015. Stages of colonialism in Africa: From occupation of land to occupation of being. Journal of Social and Political Psychology 3(1): 239-256. doi:10.5964/jspp.v3i1.143

Constitution of South Africa. 1996. http://www.justice.gov.za/legislation/constitution/SAConstitutionweb-eng.pdf (Accessed 7 May 2019).

Cornell, J. and S. Kessi. 2017. Black students' experiences of transformation at a previously "white only" university: A photovoice study. Ethnic and Racial Studies 40(11): 1882-1899. doi: 10.1080/01419870.2016.1206586

Dolmage, J. T. 2017. Academic ableism: Disability and higher education. Ann Arbor, MI: University of Michigan Press.

Eisenberg, D., E. Golberstein and J. B. Hunt. 2009. Mental health and academic success in college. The B. E. Journal of Economic Analysis and Policy 9(1): Article 40. doi:10.2202/1935-1682.2191

Eisenberg, D., S. E. Gollust, E. Golberstein and J. L. Hefner. 2007. Prevalence and correlates of depression, anxiety, and suicidality among university students. American Journal of Orthopsychiatry 77(4): 534-542. doi:10.1037/0002-9432.77.4.534

Employment Equity Act Revised Draft code of Good Practice for the Employment of Persons with Disabilities. 2015. http://www.labour.gov.za/DOL/downloads/legislation/Codes\%20of\%20Good $\% 20$ Practice/employment-equity/Code $\% 20$ of $\% 20$ Good $\% 20$ Practice $\% 20$ on $\% 20$ Key $\% 20$ Aspects $\% 20$ on $\% 20$ the $\% 20$ Employment $\% 20$ of $\% 20$ People $\% 20 w i t h \% 20$ Disabilities.pdf (Accessed 7 May 2019).

Evans, T. M., L. Bira, J. B. Gastelum, L. T. Weiss and N. L. Vanderford. 2018. Evidence for a mental health crisis in graduate education. Nature Biotechnology 36(3): 282-284.

Faculty of Health Science Students. 2016. Demands made by the students of the Faculty of Health Sciences on Tuesday, $20^{\text {th }}$ September 2016. https:/vula.uct.ac.za/access/content/group/25f04c1d1bf4-497a-bdb5-e12357b066ef/Test/1.\%20Undergraduate $\% 20$ Health\%20Science\%20Faculty \%20Student\%20Demands.pdf (Accessed 19 May 2019).

Fanon, F. 1991. Black skin, white masks. New York: Grove Weidenfeld.

Frances, A. 2013. Saving normal: An insider's revolt against out-of-control psychiatric diagnosis, DSM5, big pharma, and the medicalization of ordinary life. New York: Willaim Morrow.

Frances, A. J. and T. Widiger. 2012. Psychiatric diagnosis: Lessons from the DSM-IV past and cautions for the DSM-5 future. Annual Review of Clinical Psychology 8: 109-130. doi: 0.1146/annurevclinpsy-032511-143102

Gallagher, R. 2014. National survey of counseling center directors. Alexandria, VA: National Association of Counseling Services. http://d-scholarship.pitt.edu/28178/1/survey_2014.pdf (Accesed 3 May 2019).

Goodley, D. 2018. Understanding disability: Biopsychology, biopolitics, and an in-between-all politics. Adapted Physical Activity Quarterly 35(3): 308-319. doi:10.1123/apaq.2017-009

Grech, S. 2015. Decolonising Eurocentric disability studies: Why colonialism matters in the disability and global South debate. Social Identities 21(1): 6-21. doi:10.1080/13504630.2014.995347

Institutional Reconciliation and Transformation Commission of the University of Cape Town. 2019. Final Report. https://www.news.uct.ac.za/downloads/irtc/IRTC_Final_Report_2019.pdf (Accessed 13 May 2019).

Insel, T. 2013. Director's blog: Transforming diagnosis. www.nimh.nih.gov/about/director/2013 /transforming-diagnosis.html (Accessed 13 May 2019).

IRTC see Institutional Reconciliation and Transformation Commission of the University of Cape Town.

Kirmayer, L. and I. Gold. 2012. Re-socializing psychiatry: Critical neuroscience and the limits of reductionism. In Critical neuroscience: A handbook of the social and cultural contexts of neuroscience, ed. S. Choudhury and J. Slaby, 307-330. Wiley-Blackwell: Chichester.

Kirmayer, L. J. and D. Pedersen. 2014. Toward a new architecture for global mental health. 
Transcultural Psychiatry 51: 759-776. doi:10.1177/1363461514557202

Klein, M. 1946. Notes on some schizoid mechanisms. International Journal of Psychoanalysis 27: 99110.

LaFrance, M. N. and S. McKenzie-Mohr. 2013. The DSM and its lure of legitimacy. Feminism and Psychology 23(1): 119-140. doi:10.1177/0959353512467974

Lopez, M. F., W. M. Compton, B. F. Grant and J. P. Beiling. 2007. Dimensional approaches in diagnostic classification: A critical appraisal. International Journal of Methods in Psychiatric Research 16(S1): S6-S7. doi:10.1002/mpr.213

Lund, C., S. Kleintjes, R. Kakuma and A. J. Flisher. 2010. Public sector mental health systems in South Africa: Inter-provincial comparisons and policy implications. Social Psychiatry and Psychiatric Epidemiology 45(393): 393-404. doi:10.1007/s00127-009-0078-5

Lund, C., L. Myer, D. J. Stein, D. R. Williams and A. J. Flisher. 2013. Mental illness and lost income among adult South Africans. Social Psychiatry and Psychiatric Epidemiology 48(1): 845-851. doi:10.1007/s00127-012-0587-5

Mabasa, N. 2018. Suicide on campuses: Spate of deaths raises alarm. https://www.google.co.za/ $\mathrm{amp} / \mathrm{s} / \mathrm{www}$.dailymaverick.co.za/article/2018-10-28-suicide-on-campus-spate-of-deaths-raisesalarm/amp/ (Accessed 19 May 2019).

Martín-Baró, I. 1994. Writings for a liberation psychology. Cambridge, MA: Harvard University Press.

Murphy, D. 2015. "Deviant deviance": Cultural diversity in DSM-5. In History, philosophy and theory of the life sciences: Vol. 10. The DSM-5 in perspective: Philosophical reflections on the psychiatric Babel, ed. S. Demazeux and P. Singy, 97-110. New York, NY, US: Springer Science + Business Media.

Mills, C. 2015. The psychiatrization of poverty: Rethinking the mental health-poverty nexus. Social and Personality Psychology Compass 9(5): 213-222. doi:10.1111/spc3.12168

Ngubane, P. 2019. Mental health difficulties associated with re-admission appeal applications at the University of Cape Town. Unpublished masters' dissertation.

Oxford University. 2017. Student mental health policy. http://www.ox.ac.uk/sites/files/oxford/ field/field_document/Student $\% 20$ Mental $\% 20$ Health\%20Policy\%20-\%20PDF\%20Version.pdf) (Accessed 18 July 2016).

Patel, V. 2012. Global mental health: From science to action. Harvard Review of Psychiatry 20: 6-12. doi:10.3109/10673229.2012.649108

Patel, V. 2014. Why mental health matters to global health. Transcultural Psychiatry 51: 777-789. doi: $10.1177 / 1363461514524473$

Patel, V., R. Araya, S. Chatterjee, D. Chisholm, A. Cohen, M. De Silva, ... M. van Ommeren. 2007. Treatment and prevention of mental disorders in low-income and middle-income countries. Lancet, 370: 991-1005. doi:10.1016/S0140-6736(07)61240-9

Prince, M. J., A. Rahman, R. Mayston and B. Weobong. 2014. Mental health and the global health and development agenda. In Global mental health: Principles and practice, ed. V. Patel, H. Minas, A. Cohen and M. J. Prince, 102-115. New York: Oxford University Press.

Promotion of Equality and Prevention of Unfair Discrimination Act. 2000. http://www.justice.gov.za/ legislation/acts/2000-004.pdf (Accessed 7 May 2019).

Rhodes Must Fall Movement. 2015. UCT Rhodes Must Fall mission statement. http://www.jwtc.org.za/ resources/docs/salon-volume-9/RMF_Combined.pdf (Accessed 8 May 2019).

RMF see Rhodes Must Fall.

Samuels, E. 2014. Fantasies of identification: Disability, gender, race. New York: New York Univesity Press.

Shifrer, D. 2013. Stigma of a label: Educational expectations for high school students labeled with learning disabilities. Journal of Health and Social Behavior 54(4): 462-480. doi: $10.1177 / 0022146513503346$ 
Strategic Policy Framework on Disability for the Post-School Education and Training System. 2018. http://www.dhet.gov.za/SiteAssets/Gazettes/Approved\%20Strategic\%20Disability\%20Policy\%2 0Framework\%20Layout220518.pdf (Accessed 7 May 2019).

Summerfield, D. 2002. ICD and DSM are contemporary cultural documents. British Medical Journal 324: 914. doi:10.1136/bmj.324.7342.914/b

Swartz, S., A. Mahali, R. Moletsane, E. Arogundade, E. N. Khalema, A. Cooper and C. Groenwwald. 2018. Studying while black: Race, education and emancipation in South African universities. Cape Town: HSRC Press.

Thomas, C. 2007. Sociologies of disability, "impairment", and chronic illness: Ideas in disability studies and medical sociology. London: Palgrave.

Titchkosky, T. and K. Aubrecht. 2009. The anguish of power: Remapping mental diversity with an anticolonial compass. In Breaching the colonial contract: Anti-colonialism in the US and Canada, ed. A. Kempf, 179-199. Dordrecht: Springer.

Tol, W. A. 2015. Stemming the tide: Promoting mental health and preventing mental disorders in lowand middle-income countries. Global Mental Health 2(11). doi:10.1017/gmh.2015.9

United Nations General Assembly. 2007. Convention on the Rights of Persons with Disabilities: Resolution / adopted by the General Assembly, 24 January 2007, A/RES/61/106. https://www.refworld.org/docid/45f973632.html (Accessed 7 May 2019).

Universities UK. 2015. Student mental well-being in higher education: Good practice guide. https://www.universitiesuk.ac.uk/policy-and-analysis/reports/Documents/2015/student-mentalwellbeing-in-he.pdf (Accessed 15 May 2019).

University of Calgary. n.d. Campus mental health strategy. https://www.ucalgary.ca/ provost/files/provost/15-unv-018-mental_health_strategy_final.pdf (Accessed 19 July 2016).

University of Cape Town. 2018. Transformation report 2018. https://www.news.uct.ac.za/ images/userfiles/downloads/media/2018-UCT-Transformation-Report.pdf (Accessed 3 May 2019).

University of Western Australia. 2015. University policy on mental health. http://www.hr.uwa.edu.au/ policies/policies/equity/mental-health (Accessed 19 July 2016).

Watters, E. 2010. Crazy like us: The globalisation of the American psyche. New York: Free Press.

Whiteford, H. A., A. J. Ferrari, L. Degenhardt, V. Feigin and T. Vos. 2015. The global burden of mental, neurological and substance use disorders: An analysis from the Global Burden of Disease Study 2010. PLoS ONE 10(2): e0116820. doi:10.1371/journal.pone.0116820

Whitley, R. 2015. Global mental health: Concepts, conflicts, controversies. Epidemiology and Psychiatric Services 24: 285-291. doi:10.1017/S2045796015000451

WHO see World Health Organisation.

World Health Organisation. 2002. Prevention and promotion in mental health. Geneva: World Health Organization.

World Health Organisation. 2005. Mental health: Facing the challenges, building solutions. Report from the WHO European Ministerial Conference. Copenhagen, Denmark: WHO Regional Office for Europe.

World Health Organization. 2010. mhGAP intervention guide for mental, neurological and substance use disorders in non-specialized health settings. Geneva, Switzerland.

World Health Organization. 2013. Mental health action plan 2013-2020. WHO: Geneva, Switzerland.

Xiao, H., D. M. Carney, S. J. Joun, R. A. Janis, L. G. Castonguay, J. A. Hayes and B. D. Locke. 2017. Are we in crisis? National mental health and treatment trends in college counseling centers. Psychological Services 14(4): 407-415. doi: 10.1037/ser0000130 